\title{
For Once
}

\section{JOHN S. HATCHER}

To be, but for one All Hallows Eve

Something other than ourselves,

Defying gravity and space,

Freed from every law of science

and of God,

Mocking every trace

Of decorum and grace

That constrains our inmost longings.

Let's indulge in fantasy this one brief night.

Unveil our secret selves from shame,

Loose our inner demons to revel,

To un-disguise ourselves

For near ones and neighbors

To peer beneath our daily masks. 